\title{
The Role of Teachers' Speak Speed in Finance Class Learning
}

\author{
Liljun Liu \\ Institute of economic and trade \\ Shijiazhuang University of Economics \\ Shijiazhuang, China \\ blue800410@126.com
}

\author{
Rufei Zhang \\ Institute of economic and trade \\ Shijiazhuang University of Economics \\ Shijiazhuang, China \\ zhangrufei1982@163.com
}

\begin{abstract}
Classroom learning is the main channel to learn. Discussing class learning pattern of students provides reliable theoretical basis for class teaching, which also has practical significance to promote the teaching effect and learning efficiency. Consequently, this paper, which aims at the teachers' speak speed during the learning process of Finance class, give a credible research conclusion through the deep exploration of the effects it has on classroom learning.
\end{abstract}

Keywords-Finance; Teachers' speak speed; Classroom learning Introduction

\section{INTRODUCTION}

In recent years, as the second language teaching research significant development, people pay a large amount of attention to the influence of speaking speed to language learner.Gao Yande(1993),Meng Guo(1995),Shi Peiwen(1997),etc pointed out that speaking speed is one of the main reasons influence foreign students to learn Chinese.Liu Qian (1997)through calculation pointed out the speaking speed of CCTV news program is about 280-300 words. Zhang Xianbin,Ding Gang(2003)considered that the speaking speed of teaching should slightly slower than the normal communication, which is about 200 words per minute.

In terms of practice, it is great impact of teachers' speaking speed to students' class learning, but students' learning ability is different, so there is a problem between teachers' speaking speed and students' working memory ability. When students' working memory ability less than the teacher speaking speed, they can not receive the knowledge completely. In addition, different curricula have great impact to students when they receive knowledge.

Therefore, this paper aims at Finance research particularly the influence of teacher speaking speed to student class learning.

\section{RESEARCH DESIGN}

\section{A. Research Variable Definition}

1) Working memory span: In 1974, Baddeley and Hitch gave a conception of working memory. Working memory is a kind of memory system, which can store and process information but the capability of it is limited. Working memory span is the index to measure working memory.Daneman and Carpenter (1980) discovered that working memory span and learning grade have dramatic relativity.

2) Teachers' speaking speed:Teachers' speaking speed is the speed when teachers are teaching. Teacher speaking speed can be grouped into three types, fast (280words/min), intermediate (200words/min), and slow(120words/min).

3) Class learning result:After class learning, students have a test immediately in the situation of no reviews. Grade index of students is the test scores learning in that class.

\section{B. Working Memory Test Software and Real Test}

1) Propose: Working memory span be tested to choose people who should be the next examiners.

2) The subjects: Second grade 232 examiners.male104, female128.

3) Programming working memory test: Refer to the working memory span which test by the former researchers, using addition task scan to measure examiners' working memory span.

4) The process of working memory span test: Examiners should be tested in computer room and the test program scoring automatically.

\section{Teaching Experiment Research Design}

1) Propose:Investigating the impact and interaction of teachers' speaking speed and students working memory span to class learning in Finance class teaching.

2) Hypothesis: Hypothesis one: Working memory span influence the class learning grades of students. High scope students have better grade and vice versa.

Hypothesis two: Teachers' speed influences the class learning grade of students. Slow speed have better grade and vice versa.

3) The subjects: According to the result of experiment one, students be divided into high scopes and low scopes randomly.Secondly,high scope and low scope groups be randomly divided into three groups respectively, six groups in all.

4) Experiment design: This research be designed into $3 * 2$ groups. The first element is teachers' speaking speed, which be divided into fast, intermediate, slow three levels. The second element is working memory scan, which be 
divided into high scope and low scope. three high scope groups and three low scope groups should be accepted three different speaking speed teaching at random. After that, same examination papers should be used to test examiners.

\section{RESEARCH RESULT AND ANALYSIS}

\section{A. Measure Working Memory Span}

Through the test of working memory span, 232 students' working memory span ranged distribution is 2-7,average value is 5.01,standard deviation is 1.56.Result as shown in table 1:

As to inspect if gender have impacts to working memory scan, t-test should be used to gender diversity. As table 2 shows, we can see that male and female have no difference in working memory scan

TABLE I. SUBJECTS BASIC INFORMATION AND WORKING MEMORY SPAN TEST RESULT

\begin{tabular}{|l|l|l|l|}
\hline \multirow{2}{*}{ Table Head } & \multicolumn{3}{|c|}{ Table Column Head } \\
\cline { 2 - 4 } & Table column subhead & Subhead & Subhead \\
\hline copy & More table copy & & \\
\hline
\end{tabular}

so there is no need to consider the influence of gender.

TABLE II. WORKING MEMORY SPAN GENDER DIVERSITY

\begin{tabular}{|c|c|c|c|c|c|}
\hline Gender & N & Mean & SD & t & P \\
\cline { 1 - 4 } Male & 104 & 4.9 & 1.54 & \multirow{2}{*}{0.079} & \multirow{2}{*}{0.949} \\
\hline Female & 128 & 5.1 & 1.58 & & \\
\hline
\end{tabular}

Collecting the 60 front score students and the 60 last score students of working memory scan, 120 people in total, and comparing if the diversity exist in two working memory groups. Result as shown in table 3 .We can see that the difference between the high and low groups is dramatical.Two different groups have different working memory scan indeed. More research can be continuing.

\section{B. Class Learning Effect in Different Speaking Speed}

Analyzing data to exam if working memory scan and teachers' speak speed have impacts to students' class learning. As shown in table 4:

TABLE III. DIVERSITY COMPARISON OF HIGH AND LOW WORKING MEMORY SPAN GROUPS

\begin{tabular}{|c|c|c|c|c|c|}
\hline Memory scan & N & Mean & SD & t & P \\
\hline High group & 60 & 6.63 & 0.34 & \multirow{2}{*}{32.722} & \multirow{2}{*}{0.000} \\
\hline Low group & 60 & 2.79 & 0.78 & & \\
\hline
\end{tabular}

TABLE IV. UNDER THE DIFFERENT SPEAKING SPEED CONDITIONS STUDENTS' CLASS LEARNING SCORES OF DIFFERENT WORKING MEMORY SCAN GROUPS

\begin{tabular}{|c|c|c|c|c|}
\hline Level of scan & Level of speed & N & M & SD \\
\hline Low scope & fast & 20 & 52.86 & 9.14 \\
\hline & intermediate & 20 & 54.23 & 11.65 \\
\hline & slow & 20 & 70.71 & 6.59 \\
\hline High scope & fast & 20 & 61.79 & 15.97 \\
\hline & intermediate & 20 & 80.77 & 8.97 \\
\hline & slow & 20 & 81.79 & 14.02 \\
\hline
\end{tabular}

Analyzing $2 * 3$ variance to class learning results. The first element is working memory scan, and the second element is teachers' speaking speed. Variance Analysis Result as shown in table 5:

TABLE V. THE VARIANCE ANALYSIS TABLE OF SCAN AND SPEAKING SPEED ELEMENTS

\begin{tabular}{|c|c|c|c|c|c|}
\hline $\begin{array}{c}\text { Source of } \\
\text { variation }\end{array}$ & SS & DF & MS & F & P \\
\hline & & 1 & 985.45 & 29.55 & 0.000 \\
\hline speed & 915.02 & 2 & 457.51 & 13.72 & 0.000 \\
\hline scan $\times$ speed & 320.25 & 2 & 160.12 & 4.80 & 0.021 \\
\hline error & 3834.78 & 115 & 33.35 & & \\
\hline total & 6055.49 & 120 & & & \\
\hline
\end{tabular}

From variance analysis table can be seen, the interaction of the main effect of working memory scan and teachers' speaking speed is dramatically. High scope students' effect is better than the low scope students. As teachers' speaking speed more fast, students' score descend dramatically. Working memory scan and teachers'speaking speed have significant interaction. In order to explore their relationship furthermore, to comparing the class learning score in different working memory students and different speaking speed teachers. Simply effect analysis at first, then comparing on different times. Simply effect analysis results as shown in table 6,after comparing results as shown in table 7:

TABLE VI. SIMPLY EFFECT ANALYSIS OF DIFFERENT SPEAKING SPEED AND SCAN

\begin{tabular}{|c|c|c|c|c|c|c|}
\hline & $\begin{array}{c}\text { Source } \\
\text { of } \\
\text { variation }\end{array}$ & SS & DF & MS & F & P \\
\hline fast & scan & 76.95 & 1 & 76.95 & 1.19 & 0.247 \\
\hline & error & 1228.61 & 19 & 64.66 & & \\
\hline intermediate & total & 1305.56 & 20 & & & \\
\hline & scan & 1050.32 & 1 & 1050.32 & 18.79 & 0.000 \\
\hline & error & 1062.06 & 19 & 55.90 & & \\
\hline slow & scan & 2112.38 & 20 & & & \\
\hline & error & 696.69 & 19 & 36.67 & & \\
\hline & total & 868.29 & 20 & & & \\
\hline Low scope & $\begin{array}{c}\text { Speaking } \\
\text { speed }\end{array}$ & 547.75 & 2 & 273.88 & 6.38 & 0.004 \\
\hline & error & 2489.77 & 58 & 42.93 & & \\
\hline & total & 3037.52 & 60 & & & \\
\hline High scope & $\begin{array}{c}\text { Speaking } \\
\text { speed }\end{array}$ & 703.30 & 2 & 351.65 & 6.78 & 0.003 \\
\hline & error & 3008.22 & 58 & 51.87 & & \\
\hline & total & 3711.52 & 60 & & & \\
\hline
\end{tabular}

TABLE VII. COMPARING RESULTS IN DIFFERENT SCAN

\begin{tabular}{|c|c|c|c|c|c|}
\hline $\begin{array}{c}\text { Low } \\
\text { scope }\end{array}$ & $\begin{array}{c}\text { Speed } \\
\text { level }\end{array}$ & & $\begin{array}{c}\text { Average } \\
\text { diversity }\end{array}$ & $\begin{array}{c}\text { Standard } \\
\text { error }\end{array}$ & P \\
\hline & slow & fast & 3.71 & 5.82 & 0.018 \\
\hline & & intermediate & 3.58 & 5.71 & 0.005 \\
\hline & intermediate & fast & 0.29 & 5.82 & 0.965 \\
\hline $\begin{array}{c}\text { High } \\
\text { scope }\end{array}$ & fast & intermediate & 3.81 & 6.40 & 0.011 \\
\hline & & slow & 4.02 & 6.28 & 0.003 \\
\hline & intermediate & slow & 2.05 & 6.40 & 0.979 \\
\hline
\end{tabular}


Seen from table 6 and table 7 , under the fast speaking speed condition, different memory scan students' class learning score have no difference. Under the intermediate speaking speed condition, students with different memory scan have dramatically diversity in class learning. Speaking speed has obvious difference in various general conditions. As shown in table 1,when teachers' speed is fast, students working memory regardless of the size, class learning scores is bad. When teachers' speaking speed is intermediate or slow, students class learning scores promote obviously, and students with different working memory scan have different class scores obviously as well. Slow speaking speed have the best scores, and students class learning have obvious difference when intermediate speaking speed is gong on .

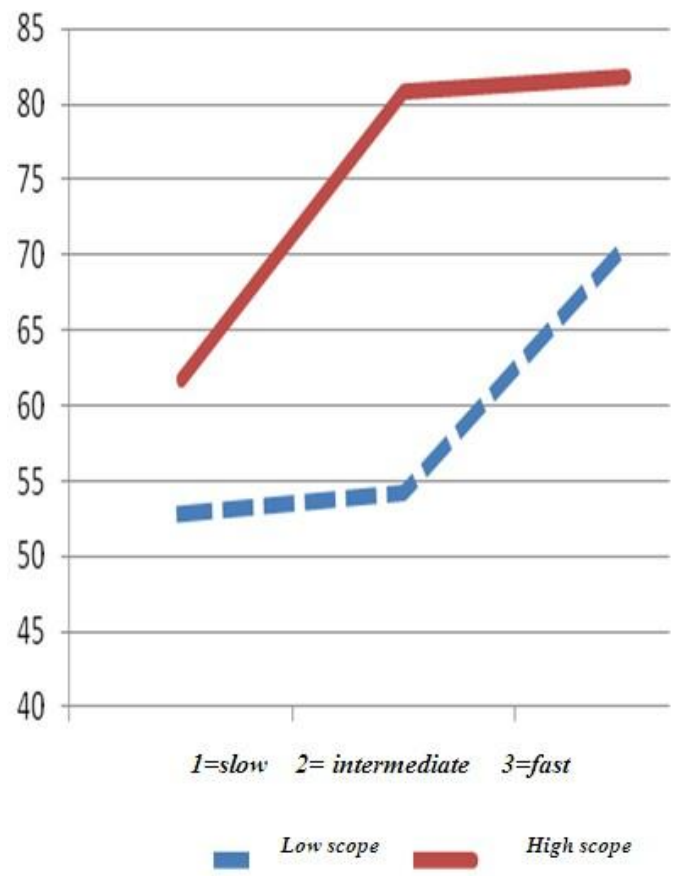

Figure 1. The influence relationship of teachers' speaking speed and students working memory scan to students' class learning

\section{CONCLUSIONS}

This paper through experiments analyzed the relationship of Finance class learning scores and college students' working memory scan, and achieving the conclusions below:

Firstly, In general, students with high working memory scan have an advantage over the students with low working memory in class learning.

Secondly, teachers' speaking speed have dramatically influence to students' class learning. Under the fast speaking speed conditions, students' class learning scores is bad. Under the intermediate and slow speaking speed conditions, students get better class scores.

Thirdly, the influence of teachers' speaking speed and students' working memory scan to class learning is interaction with each other.

\section{REFERENCES}

[1] G. Eason, B. Noble, and I. N. Sneddon, "On certain integrals of Lipschitz-Hankel type involving products of Bessel functions," Phil. Trans. Roy. Soc. London, vol. A247, pp. 529-551, April 1955. (references)

[2] Baddeley A.D. The episodic buffer: A new component of working memory. Trends in Cognitive Sciences, 2000.

[3] Daneman M, Carpenter P A. Individual differences in working memory and reading. Journal of Verbal Learning and Verbal Behavior, 1980.

[4] Gao Yande,Li Guoqiang,Guo Xu.Investigate research report of foreigner learn and use Chinese.Beijing:Beijing language college press, 1993.

[5] Meng Guo.Chinese standardization and language teaching,Tianjin proceedings of teaching Chinese as a foreign language,Tianjin:Tianjin's people press, 1993.

[6] Shi Peiwen,Li Jiyu.The role of listening training in language teaching.language teaching and study,1997. 